ARTICLE

\title{
Sources of black carbon to the Himalayan-Tibetan Plateau glaciers
}

\author{
Chaoliu Li ${ }^{1,2}$, Carme Bosch ${ }^{3}$, Shichang Kang ${ }^{2,4}$, August Andersson ${ }^{3}$, Pengfei Chen ${ }^{1,5}$, Qianggong Zhang ${ }^{1,2}$, \\ Zhiyuan Cong ${ }^{1,2}$, Bing Chen ${ }^{6}$, Dahe Qin ${ }^{4} \&$ Örjan Gustafsson ${ }^{3}$
}

Combustion-derived black carbon (BC) aerosols accelerate glacier melting in the Himalayas and in Tibet (the Third Pole (TP)), thereby limiting the sustainable freshwater supplies for billions of people. However, the sources of BC reaching the TP remain uncertain, hindering both process understanding and efficient mitigation. Here we present the source-diagnostic $\Delta^{14} \mathrm{C} / \delta^{13} \mathrm{C}$ compositions of $\mathrm{BC}$ isolated from aerosol and snowpit samples in the TP. For the Himalayas, we found equal contributions from fossil fuel ( $46 \pm 11 \%)$ and biomass $(54 \pm 11 \%)$ combustion, consistent with BC source fingerprints from the Indo-Gangetic Plain, whereas BC in the remote northern TP predominantly derives from fossil fuel combustion $(66 \pm 16 \%)$, consistent with Chinese sources. The fossil fuel contributions to BC in the snowpits of the inner TP are lower $(30 \pm 10 \%)$, implying contributions from internal Tibetan sources (for example, yak dung combustion). Constraints on BC sources facilitate improved modelling of climatic patterns, hydrological effects and provide guidance for effective mitigation actions.

\footnotetext{
${ }^{1}$ Key Laboratory of Tibetan Environment Changes and Land Surface Processes, Institute of Tibetan Plateau Research, Chinese Academy of Sciences (CAS), Beijing 100101, China. ${ }^{2}$ CAS Center for Excellence in Tibetan Plateau Earth Sciences, Beijing 100101, China. ${ }^{3}$ Department of Environmental Science and Analytical Chemistry; The Bolin Centre for Climate Research, Stockholm University, Stockholm 10691, Sweden. ${ }^{4}$ State Key Laboratory of Cryosphere Science, Cold and Arid Regions Environmental and Engineering Research Institute, CAS, Lanzhou 730000, China. ${ }^{5}$ University of CAS, Beijing 100049, China.

${ }^{6}$ Environmental Research Institute, School of Environmental Science and Engineering, Shandong University, Jinan 250100, China. Correspondence and requests for materials should be addressed to S.K. (email: shichang.kang@lzb.ac.cn) or to O.G. (email: orjan.gustafsson@aces.su.se).
} 
T he Himalaya-Hindu-Kush and Tibetan Plateau, which are collectively referred to as the Third Pole (TP), contain the largest ice mass on the planet outside of the polar regions. Unlike the Arctic and Antarctic regions, the TP is situated in a mid-latitude location and is located in the immediate vicinity of densely populated and industrialized regions. Of particular importance is its proximity to two countries (China and India) that emit the most climate-warming black carbon (BC) aerosols ${ }^{1-4}$ (Fig. 1). Therefore, the TP is considered to be one of the most vulnerable regions to effects of $\mathrm{BC}$ aerosols. The long-range transport to and deposition of $\mathrm{BC}$ aerosols in the $\mathrm{TP}$ is attracting considerable attention because of BC's effects on the transformation of hydrological and radiative forcing in the East and South Asian regions ${ }^{5-8}$. In addition, $\mathrm{BC}$ aerosols are believed to play a considerable role in the melting of mid-latitude glaciers because of both the heating of aloft air masses transported into the $\mathrm{TP}$ and the albedo effects of deposited $\mathrm{BC}^{9-13}$.

Studies based on global chemical-transport models have yielded varying predictions of source region contributions, suggesting that $\mathrm{BC}$ deposited on TP glaciers stems from heavily polluted regions on the Indian subcontinent and/or from East Asia ${ }^{4,14-17}$. However, these models are uncertain with respect to source-area emissions and air transport patterns across the highly elevated topographical mountain features of the TP. Thus, direct observational constraints are urgently needed to reduce uncertainties regarding sources of $\mathrm{BC}$ reaching the $\mathrm{TP}^{18,19}$. Because of the TP's overall inaccessibility, in situ $\mathrm{BC}$ aerosol observations for the region are lacking ${ }^{10,19-21}$, as are data on carbon isotopic compositions, which have recently been proven useful for quantitatively constraining sources of $\mathrm{BC}^{20-26}$. Furthermore, the limited comparisons of model-simulated and measured $\mathrm{BC}$ concentrations in the $\mathrm{TP}$ are not in good agreement ${ }^{4,27}$; these differences may be attributable to several causes, including uncertain emissions inventories, the complicated effects of topographic transport steering ${ }^{2}$, and source-related differences in the scavenging of different $\mathrm{BC}$ source types ${ }^{28,29}$.

Emissions inventories are severely challenged in terms of particle emissions from incomplete combustion (for example, $\mathrm{BC}$ ), especially for sources characterized by poor levels of combustion efficiency. Such sources are prevalent in South and East Asia and include the open combustion of garbage and crop residues, the use of brick kilns and household cooking/heating with firewood, and the burning of animal dung and coal briquettes. Studies of $\mathrm{BC}$ emissions inventories for Asia have reported uncertainties as high as factors of 2-4 (refs 2,30). The $\Delta^{14} \mathrm{C} / \delta^{13} \mathrm{C}$-based isotopic source-diagnostics of ambient $\mathrm{BC}$ aerosols demonstrate that emissions inventory models systematically under-predict fossil fuel-sourced BC contributions relative to biomass-sourced $\mathrm{BC}$ fractions for both India ${ }^{22}$ and China $^{21,31}$. Because BC emissions from fossil vs biomass combustion have different properties ${ }^{32}$, improved source discrimination methods may help increase the understanding of both radiative and transport processes ${ }^{33}$.

Fossil fuel-sourced BC appears to have approximately twice the particle-specific warming potential of biomass-sourced $\mathrm{BC}^{2,32}$. One major challenge facing the successful modelling of $\mathrm{BC}$ transport in mountain regions is the updraft transport from source regions to the $\mathrm{TP}^{2}$; during this process, the scavenging of aerosols on slopes remains unknown, particularly for biomass vs fossil fuel BC.

To address these uncertainties, the dual-carbon-isotope $\left(\Delta^{14} \mathrm{C}\right.$ and $\delta^{13} \mathrm{C}$ ) fingerprint of $\mathrm{BC}$, which is diagnostic for fossil fuel vs biomass combustion and for source regions, was investigated using aerosol and glacier snowpit samples collected from the hitherto most extensive geographical collection of $\mathrm{BC}$ observations on the southern, central and northern mountain chains of the TP (Fig. 1).

The natural abundance radiocarbon signal $\left(\Delta^{14} \mathrm{C}\right)$ of $\mathrm{BC}$ in the present-day atmosphere has proven to be effective in

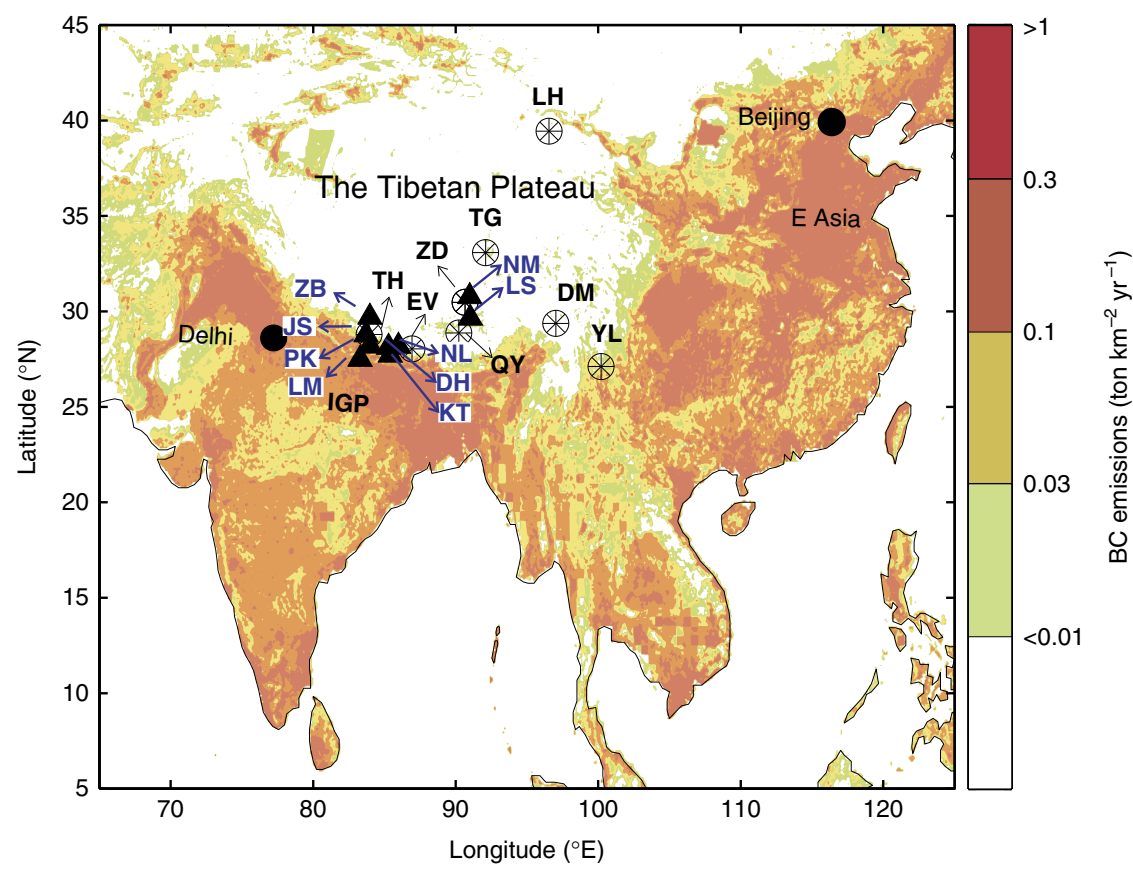

Figure 1 | Map of sampling sites. The background image presents the model-predicted BC emission inventories for South and East Asia created using MATLAB (version 2014b) based on data drawn from http://inventory.pku.edu.cn/download/download.html ${ }^{66}$. Triangles denote aerosol sampling sites, and circles denote snowpit sampling sites. NM, LS, NL, DH, KT, ZB, JS, PK and LM indicate the following aerosol stations: Namco, Lhasa, Nyalam, Dhunche, Kathmandu, Zhongba, Jomsom, Pokhara and Lumbini, respectively. LH, TG, ZD, YL, DM, QY, EV and TH represent the following glaciers: Laohugou No. 12, Xiaodongkemadi, Zhadang, Yulong, Demula, Qiangyong, East Rongbuk and Thorung, respectively. 
quantitatively apportioning the relative contributions of fossil fuel vs biomass combustion ${ }^{21,22,34}$. The clearly different $\Delta^{14} \mathrm{C}-\mathrm{BC}$ source fingerprints of South Asia $(50 \pm 8 \% \text { fossil })^{20,22}$ vs East Asia $(80 \pm 6 \% \text { fossil })^{21,31}$ allows the relative influences of BC from these two regions to the TP to be differentiated. An even higher resolution in $\mathrm{BC}$ source apportionment was recently achieved by characterizing the dual $\Delta^{14} \mathrm{C} / \delta^{13} \mathrm{C}$-BC fingerprint, which allowed the separation of the relative contributions from liquid fossil fuel, coal and biomass burning to severe haze events in China ${ }^{31}$. Thus, applying the $\Delta^{14} \mathrm{C} / \delta^{13} \mathrm{C}-\mathrm{BC}$ across the TP should facilitate identifying the sources of the $\mathrm{BC}$ that is melting the glaciers and from what process and where this $\mathrm{BC}$ originates.

In the present study, both air particles and particles deposited on glaciers were collected from multiple sites in the TP. From 2013 to 2014, bulk aerosols were collected from nine stations across two Himalayan valleys (Mustang and Langtang) and in the southern TP (Fig. 1 and Supplementary Table 1). Furthermore, snowpit samples from eight glaciers were obtained from a region spanning from the Himalayas in the south to the Qilian Mountains in the northeastern TP (Supplementary Table 2). The elemental carbon (EC) component, which is the common chemical/mass definition of $\mathrm{BC}$, was isolated from each sample via thermal-optical analysis, and evolved $\mathrm{CO}_{2}$ was purified online and collected using a cryotrap ${ }^{21,31}$. The combined $\Delta^{14} \mathrm{C}-\delta^{13} \mathrm{C}$ fingerprint of $\mathrm{BC}$ was used to identify the sources of $\mathrm{BC}$ to the Himalaya-Tibetan Plateau with respect to both source regions and the relative importance of different combustion source classes. We found approximately equal contributions from biomass burning and fossil fuel combustion to the Himalayas. Although the isotopic fingerprint is largely consistent with the Indo-Gangetic Plain (IGP) being a main source region for the Himalayas, the more ${ }^{14} \mathrm{C}$-depleted signal in the northern Tibetan Plateau corresponds to a Chinese source signature. Furthermore, the relatively contemporary ${ }^{14} \mathrm{C}$ signal of the central regions of the TP reflects less fossil fuel use than the South Asian and East Asian fingerprints, suggesting a putative internal/domestic source putatively resulting from the combustion of yak dung by local residents.

\section{Results}

$\Delta{ }^{14} \mathrm{C}$ of $\mathrm{BC}$ aerosols across the Himalayas. The air mass transport of $\mathrm{BC}$ from the heavily polluted IGP region to the Himalayas has been proposed to follow specific pathways. In particular, south-north-trending valleys, such as the Mustang and Langtang Valleys, may play important roles $^{35}$. In the present study, we observed significantly decreasing atmospheric BC concentration gradients in these two valleys (Supplementary Fig. 2), suggesting $\mathrm{BC}$ deposition and dilution as the air moves north and upward along them (Fig. 2a). Intriguingly, current ${ }^{14} \mathrm{C}-\mathrm{BC}$ signals show a consistent trend of changing $\mathrm{BC}$ source signatures along both valleys, with fossil fuel BC contributions $\left(f_{\text {fossil }}\right)$ ranging from $70 \pm 11$ to $58 \pm 3 \%$ and from $49 \pm 7$ to $23 \%$ along the south-north gradients in the Langtang and Mustang Valleys, respectively (Fig. 2a). The high $f_{\text {fossil }}$ value in the southern Langtang Valley reflects urban effects from Kathmandu, whereas those found for other southern sites are in strong agreement with the $f_{\text {fossil }}$ of BC for the IGP of northern India ${ }^{22}$. Because fossil fuel combustion-sourced BC is at least as likely to be transported over long distances, decreasing $f_{\text {fossil }}$ values moving up valleys and into the TP suggest a significant influence of local biomass-burning activities on the total $\mathrm{BC}$ load of the TP.

Another mechanism of pollutant transport into the TP from the IGP involves movement through an aloft conveyor, which gives rise to high levels at elevated tropospheric altitudes ${ }^{36,37}$. Although the $\mathrm{BC}$ aerosol concentration at Namco is very low $\left(0.09 \pm 0.02 \mu \mathrm{g} \mathrm{m}^{-3}\right)$, its fossil fuel contribution $(46 \pm 6 \%)$ falls
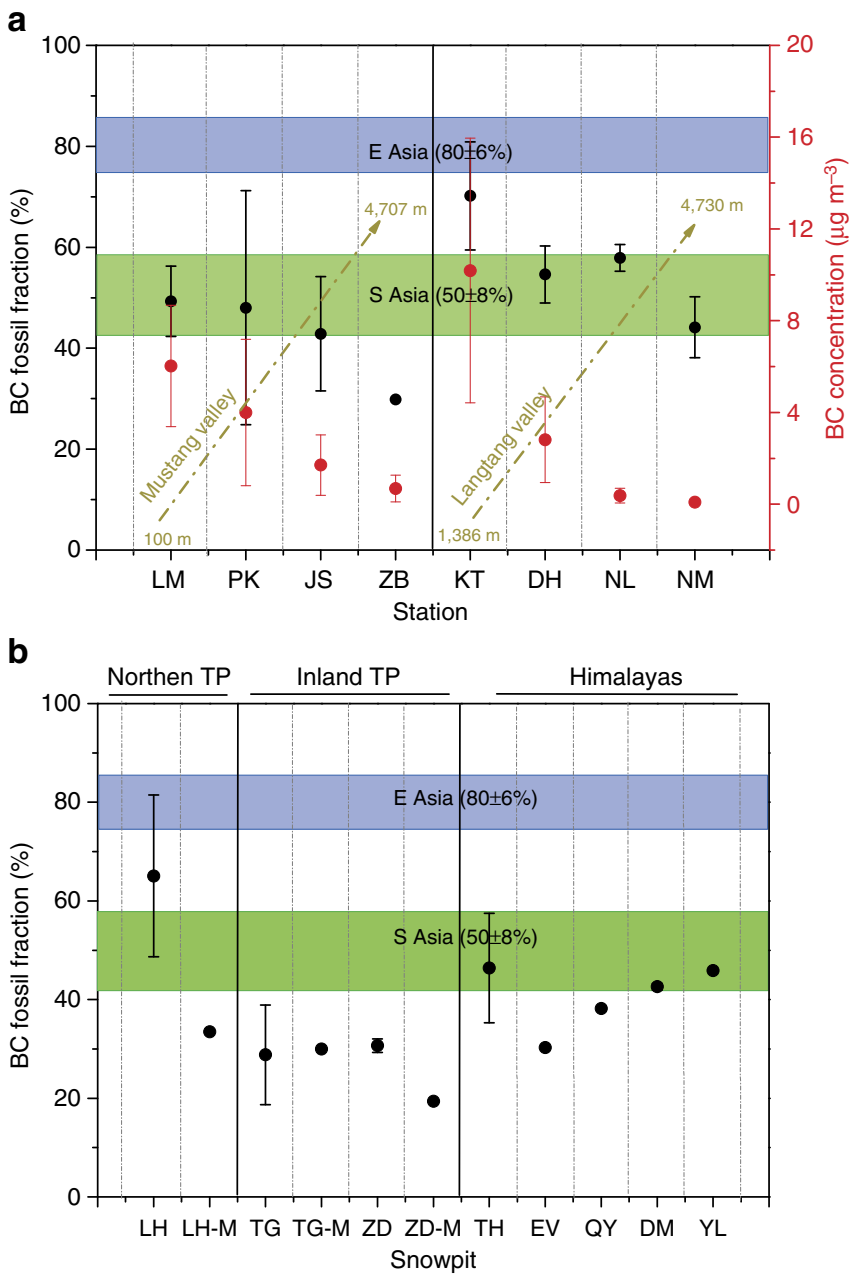

Figure 2 | Fossil fuel contributions of black carbon in the studied samples. (a) Aerosol samples collected from two valleys across the Himalayas. (b) Snowpit and snow samples collected during the monsoon period (LH-M, TG-M and ZD-M). For aerosol samples: The error bars

(1 s.d.) represent 1-4 samples collected during different seasons for each station (Supplementary Table 4). For the snowpit samples: The error bars (1 s.d.) are based on two replicates for each snowpit (one sample for EV) (Supplementary Table 6). Some bars are so small that they are hidden by symbols. Data for South Asia (solid green band) and North China (solid blue band) were adopted from refs 20,22 and refs 21,31 , respectively. To investigate the decreasing concentrations and fossil fuel contributions of $\mathrm{BC}$ from South Asia to the remote area of the TP, data for the city of Lhasa, which is heavily polluting and has a fuel profile similar to that of most Chinese cities, are excluded. The error bars of the fossil fuel contributions and $\mathrm{BC}$ concentrations correspond to $1 \mathrm{s.d}$. for samples collected on different dates. NM, NL, DH, KT, ZB, JS, PK and LM indicate the following aerosol stations: Namco, Nyalam, Dhunche, Kathmandu, Zhongba, Jomsom, Pokhara and Lumbini, respectively. LH, TG, ZD, YL, DM, QY, EV and TH represent the following glaciers: Laohugou No. 12, Xiaodongkemadi, Zhadang, Yulong, Demula, Qiangyong, East Rongbuk and Thorung, respectively.

within the range found in the atmosphere of the IGP 22,31 (Fig. 2a), suggesting that Namco receives predominantly long-range-transported pollutants from outside of the TP. These isotope-based source apportionment results confirm previous suggestions that $\mathrm{BC}$ aerosols from the IGP can be transported to the Himalayas ${ }^{38-40}$ and even further to the southern Tibetan Plateau ${ }^{19,41}$. The city of Lhasa, which is located in the southern TP, exhibits a relatively depleted ${ }^{14} \mathrm{C}-\mathrm{BC}$ signal 
(that is, reflecting a larger fossil fuel contribution) and is instead similar to that commonly found in East Asia (Supplementary Table 4). We suggest that the fuel structure of Lhasa is similar to that of urban areas across China ${ }^{21,42-44}$.

This study also assess seasonal variations in atmospheric BC concentrations and their relative source contributions in the TP because such variations are important inputs for radiative forcing assessments. The $\mathrm{BC}$ concentrations decrease during the monsoon period in the Himalayas (Supplementary Fig. 3), presumably because of heavy precipitation ${ }^{38,45}$. In this study, isotope-based source apportionment results further suggest a relative increase in fossil fuel $\mathrm{BC}$ at all of the examined stations (Supplementary Fig. 3). This is likely attributable to more efficient scavenging of biomass-sourced BC from the atmosphere via precipitation, as observed in South Asia ${ }^{46}$ and Europe ${ }^{47}$, and/or lower levels of biomass fuel consumed by local TP residents during the warmer monsoon period. East Asia may also represent a possible source during the monsoon period ${ }^{17,48}$, contributing to the slightly elevated $f_{\text {fossil }}$ values associated with this period. Consequently, fossil fuel-sourced BC plays a relatively more important role in climate forcing in the TP during the monsoon period. Because this temporal phenomenon was observed in both urban and remote areas, it may represent a general feature that could also apply to other Asian regions.

$\Delta^{14} \mathrm{C}$ of glacier snowpit BC across the TP. BC emitted from the IGP and East Asia can be transported to and deposited on glaciers in the TP, especially in its fringe areas. The BC concentrations in snowpit samples collected across the TP (Fig. 1) varied considerably (11-133 $\mathrm{ng} \mathrm{g}^{-1}$ ), in agreement with previous results reported for snowpits in the TP, with high concentrations in the northern TP (Supplementary Table 5$)^{49}$. The ${ }^{14} \mathrm{C}$ signal of snowpit BC shows clear spatial trends, with increasing levels of ${ }^{14} \mathrm{C}$ enrichment (that is, increasing contributions from biomass combustion) from the Himalayas (Thorung (TH)) and northern TP (Laohugou (LH)) to inland Tibet (Tanggula (TG) and Zhadang (ZD)) (Fig. 2b). This source-contribution trend

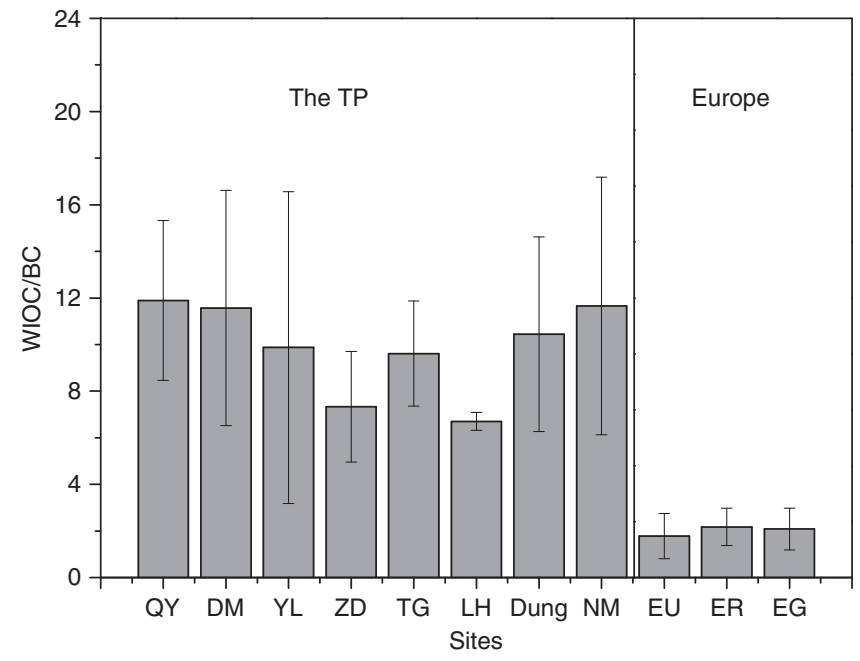

Figure 3 | WIOC/BC ratios for snowpit and aerosol samples from the Third Pole and Europe. The error bars represent 1 s.d. of the WIOC/BC ratios for each station. The sample numbers from QY, DM, YL, ZD, TG, LH, Dung, NM, EU, ER and EG were 9, 7, 6, 5, 8, 3, 9, 8, 7, 12 and 5, respectively. QY, DM, YL, ZD, TG and LH indicate the following glaciers: Qiangyong, Demula, Yulong, Zhadang, Xiaodongkemadi and Laohugou No. 12, respectively. Dung and NM refer to aerosol samples of yak dung combustion and outdoor air from Namco, respectively. EU, ER and EG refer to particles drawn from urban areas ${ }^{25}$, remote areas $^{47}$ and glacial areas across Europe ${ }^{26}$, respectively. was independent of the BC concentration (Supplementary Fig. 4), demonstrating that ${ }^{14} \mathrm{C}$ provides more distinct source-diagnostic information than the concentration and that fossil fuel-sourced $\mathrm{BC}$ is transported from outer source regions to central areas in the TP. The fossil fuel contributions of BC found in all of the TP snowpit samples were lower than those found in European Alpine ice cores $(83 \pm 2 \%)$ (ref. 26). The BC from a European glacier was shown to exhibit a high ratio of fossil fuel contributions, with $f_{\text {fossil values succeeding those of urban areas }}$ in the region; these findings suggested the preferential long-range transport of $\mathrm{BC}$ from fossil fuels compared ${ }^{23}$ with that of $\mathrm{BC}$ from biomass combustion. The water-insoluble organic carbon (WIOC)/BC values were found to be much higher in the snowpits of the TP glacier than in the European Alps and similar to those of Namco aerosol and biomass-burning-sourced particles (Fig. 3). These findings are consistent with locally sourced biomass combustion particles contributing substantially to the BC loading of TP glacier region (Fig. 4). Taken together, the relatively enriched ${ }^{14} \mathrm{C}$ and high $\mathrm{WIOC} / \mathrm{BC}$ ratios suggest that a large proportion of $\mathrm{BC}$ in the $\mathrm{TP}$ glaciers is derived from biomass burning. Spatially, the highest fossil fuel contribution $(66 \pm 16 \%)$, which was observed in the remote northernmost snowpit at LH in the northern TP, is similar to those commonly found in the developing areas of East Asia $(80 \pm 6 \%)$ (refs 21,31) and thus reflects the effects of anthropogenic emissions transported from north-western China to glaciers in the northern TP (Fig. 1). Correspondingly, the fossil fuel BC contributions among glaciers along the southern slopes of the Himalayas $(\mathrm{TH})(46 \pm 11 \%)$ reflect the effects of IGP $(50 \pm 8 \%)$ (refs 20,22). Hence, source-diagnostic BC observations for TP glaciers in both the northern and southern fringe regions are consistent with $\mathrm{BC}$ aerosols originating from East and South Asia, respectively.

We also found that ${ }^{14} \mathrm{C}$ is enriched (that is, more contemporary) in snowpit $\mathrm{BC}$ in the inland TP (for example, TG and $\mathrm{ZD}$ ) relative to the levels in the IGP and East Asia (Fig. 2b). This finding may indicate sizeable contributions of BC emissions from local TP residents who largely rely on burning yak dung for daily cooking

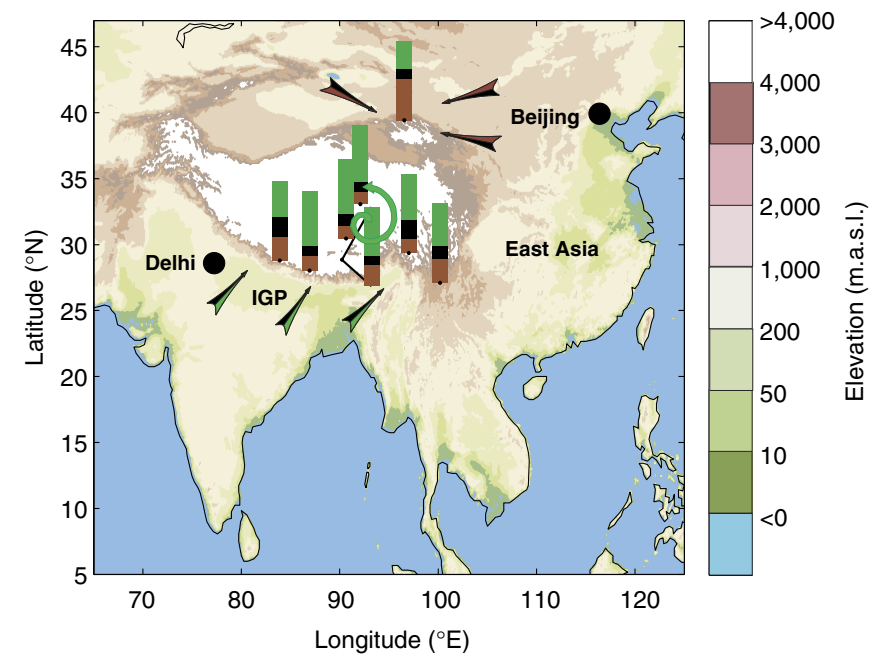

Figure 4 | Relative contributions of the combustion of three fuel classes to Third Pole snowpit sample black carbon. Green, black and brown bars represent biomass, liquid fossil fuels and coal combustion, respectively. The source signatures of the ${ }^{14} \mathrm{C}$ - and ${ }^{13} \mathrm{C}$ of these three fuels are presented as mean \pm s.d. values in Supplementary Table 7. Black and brown arrows denote the transport of $\mathrm{BC}$ from East Asia, black and green arrows indicate the transport of $B C$ from South Asia, and green arrows represent $B C$ emissions from local/domestic activities in the TP. 
and heating ${ }^{50-52}$, thereby significantly affecting glacier $\mathrm{BC}$ in the inland TP. Consequently, whereas previous research has assumed that the $\mathrm{BC}$ in the TP stems mainly from long-range transport processes from either the IGP or East Asia, ${ }^{4,15}$, the enriched ${ }^{14} \mathrm{C}$ in the $\mathrm{BC}$ of inland TP glaciers (for example, ZD and TG) found here more likely indicates contributions from local, previously overlooked Tibetan sources. Taken together, the results of this extensive observation-based source-diagnostic study provide strong isotope-based evidence that biomass-sourced BC plays a quantitatively more important role in TP glacier melting than fossil fuel-sourced BC, especially in the inland TP, and presumably arises mainly from domestic sources ${ }^{17}$.

\section{Discussion}

A combined analysis of the $\delta^{13} \mathrm{C}$ and $\Delta^{14} \mathrm{C}$ fingerprints can further refine the source apportionment of $\mathrm{BC}^{20-22}$. The contributions of coal-combustion-sourced $\mathrm{BC}$ are the most significant for the $\mathrm{LH}$ glacier, which is in line with the high coal-consumption patterns characteristic of north-western China (Fig. 4) (ref. 31). Correspondingly, the $\delta^{13} \mathrm{C}$ signal corresponding to liquid fossil fuel is in good agreement with the $\delta^{13} \mathrm{C}$ of $\mathrm{BC}$ in glaciers in the Himalayas and inland TP, highlighting the influence of South Asian sources. Taken together, the $\Delta^{14} \mathrm{C} / \delta^{13} \mathrm{C}-\mathrm{BC}$ signals further decipher the sources of $\mathrm{BC}$ across the $\mathrm{TP}$, revealing an approximately equal influence of biomass combustion sources within the southern TP/Himalayas that mainly stem from emissions from the IGP. We also found that the northern TP is influenced by emissions from north-western China, whereas the inland TP experiences non-negligible effects from internal domestic sources of BC (Fig. 4). These observation-based source apportionments of $\mathrm{BC}$ facilitate improved modelling of the climatic and hydrological effects of BC in the TP and guide policy actions aimed to effectively mitigate emissions.

\section{Methods}

Snowpit sample collection. Eight snowpits were collected from col or firn basins of glaciers in the TP during May and June of 2012-2014 (Fig. 1 and Supplementary Table 2). Snow samples were collected at a vertical resolution of $20-30 \mathrm{~cm}$ using a pre-combusted stainless steel shovel $\left(550{ }^{\circ} \mathrm{C}, 6 \mathrm{~h}\right)$ and were stored in sterile $5-\mathrm{L}$ Whirl-Paks bags (Nasco, Fort Atkinson, WI, USA). The frozen samples were transported back to the laboratory and transferred into polytetrafluoroethylene bags. The samples were allowed to thaw at room temperature and were then subjected to ultrasonic treatment and filtration through a pre-combusted and pre-weighted quartz fibre filter ( $47 \mathrm{~mm}$ in diameter, Whatman Corp) twice. Samples from clean and dirty snow layers were filtered separately, and the filtered particles were freeze-dried and weighed. Subsequently, the filters were folded, wrapped in pre-combusted aluminium foil, packed into airtight plastic bags, and stored at $-20^{\circ} \mathrm{C}$ for further analysis. The water volume that passed through each filter was recorded. Initial tests showed that the split times between the WIOC and $B C$ values for snowpit samples with heavy particle loads were longer (later), resulting in the determination of lower or even zero BC concentrations because of the difficulties associated with resolving small changes in laser signals under such heavy loading conditions. To mitigate this problem, we sought to maintain a low particle load on the filter to more readily resolve the split time.

Samples from snowpits were collected during the spring, mainly during the non-monsoon period (September-May), rather than all year. This is because snow deposited during the monsoon period occasionally melts because recent dramatic warming patterns $s^{53,54}$, increased light-absorbing particles in glacier ${ }^{13}$ and decreased precipitation levels $s^{55}$. Therefore, fresh snow samples were also collected from the firn basins of three glaciers (ZD, TG and LH) within $12 \mathrm{~h}$ of heavy snow events during the monsoon period (Supplementary Table 2). Potential source regions for snow events during the monsoon period were estimated using air mass backward trajectories (http://www.arl.noaa.gov/ready/hysplit4.html). The air masses of these monsoon period snowfall events moved from West China and the Hexi Corridor to the LH glacier (Supplementary Fig. 5a) and from South Asia (Supplementary Fig. $5 \mathrm{~b}, \mathrm{c}$ ) to the TG and ZD glaciers, respectively.

Aerosol sample collection. Total suspended particle (TSP) samples were collected from pre-combusted quartz fibre filters ( $90 \mathrm{~mm}$ in diameter, Whatman Corp.) installed at seven stations along two valleys (the Mustang and Langtang Valleys) across the Himalayas from the IGP to the TP from January of 2013 to December of 2014 using TSP cyclones at a flow rate of $100 \mathrm{lmin}^{-1}$ (TH150-A, Wuhan
Tianhong INST Group) (Supplementary Table 1). Each sample was collected for $24 \mathrm{~h}$ during the non-monsoon season and for $48 \mathrm{~h}$ during the monsoon season. The collected samples were kept frozen until analysis, which used the thermal-optical transmittance (TOT) method (detailed below). TSP samples were also collected from the city of Lhasa and from the Namco station between 2013 and 2014. Because of the low BC concentrations at the Namco station, each aerosol sample was collected for $\sim 20$ days using the same TSP cyclone. Although some of the collected thermodynamically unstable organic species may have been chemically transformed by strong oxidants during these long sampling periods, the carbon isotopic compositions of collected recalcitrant $\mathrm{BC}$ were expected to remain stable

BC measurement. The BC mass contents of the filtered snow and TSP samples were quantified using the TOT technique. Briefly, filters were acidified by fumigation in open glass Petri dishes held in a desiccator with $>37 \% \mathrm{HCl}$ acid for $24 \mathrm{~h}$ to remove carbonates and were subsequently dried at $60^{\circ} \mathrm{C}$ for $1 \mathrm{~h}$ to remove any remaining $\mathrm{HCl}$ acid. A $1.5 \mathrm{~cm}^{2}$ piece of acid-treated filter was cut out and analysed using a TOT carbon analyser (Sunset Laboratory, Tigard, OR, USA) following the National Institute for Occupational Safety and Health (NIOSH) method 5040 to determine $\mathrm{BC}$ and organic carbon (OC) concentrations of the aerosol samples and the WIOC concentrations of the particles from the collected snow sample. Sucrose standard and other reference materials were also subjected to these measurements ${ }^{21}$

$\mathrm{CO}_{2}$ isolation and $\Delta^{14} \mathrm{C}$ and $\delta^{13} \mathrm{C}$ analysis. The filter area required for the subsequent ${ }^{14} \mathrm{C}$ measurements was determined based on the measured $\mathrm{BC}$ concentration. The filters were then subjected to the Sunset-NIOSH-5040 protocol, and the $\mathrm{CO}_{2}$ produced was cryotrapped during the $\mathrm{BC}$ combustion phase after removing the water and sulfur-containing gases online ${ }^{21}$. Purified $\mathrm{CO}_{2}$ was then transferred in flame-sealed glass ampules to the United States National Science Foundation, National Ocean Science Accelerator Mass Spectrometry facility at the Woods Hole Oceanographic Institution (Woods Hole, MA, USA). The radiocarbon analysis results are reported as per mil deviations $\left(\Delta^{14} \mathrm{C}\right)$ relative to National Bureau of Standards oxalic acid. The parameters of the studied samples are listed in Supplementary Tables 4 and 6 . This type of analysis has been used in previous studies on aerosol ${ }^{21-23,25,31}$ and snow/ice core samples ${ }^{26,56}$. Because of the inert (unreactive) nature of $\mathrm{BC}$, minimal isotopic fractionation is expected during its long-range transport ${ }^{2,31}$. For snowpit samples, isotopic measurements were performed by assuming that the BC collected by filtration ${ }^{57,58}$ (here, $77 \pm 17 \%$; $n=16$ (Supplementary Fig. 1)) is representative of the total BC content found in snow. A putative effect of OC charring on the estimated $\mathrm{BC} \Delta^{14} \mathrm{C}$ was also considered. The split time between OC and BC was similar for the snowpits and aerosols, suggesting that such effects are limited (Supplementary Table 3), which is consistent with earlier sensitivity test results for charring ${ }^{21}$.

Isotope mass balance model. A simple binary mixing model was used to obtain the fractional contributions of biomass ( $\left.f_{\text {biomass }}\right)$ and fossil fuels $\left(f_{\text {fossil }}=1-f_{\text {biomass }}\right)$ to the carbonaceous aerosol components of the measured samples:

$$
\Delta \Delta^{14} C_{B C}=\Delta \Delta^{14} C_{\text {biomass }} \times f_{\text {biomass }}+\Delta^{14} C_{\text {fossil }} \times\left(1-f_{\text {biomass }}\right),
$$

where $\Delta^{14} \mathrm{C}_{\mathrm{BC}}$ is the measured radiocarbon content of the $\mathrm{BC}$ component, and $\Delta{ }^{14} \mathrm{C}_{\text {fossil }}$ is $-1,000 \%$. The $\Delta^{14} \mathrm{C}$ biomass end member falls between $+70 \%$ (freshly produced biomass) and $+225 \%$ (wood). A large portion of the TP is covered by grassland, and yak dung is the main fuel source used by local residents. In contrast, forests are distributed across the southeastern TP, and in this area, wood is the local residents' main fuel source. Therefore, a $\Delta{ }^{14} C_{\text {biomass }}$ end member of $+70 \%$ (ref. 59) was adopted for samples obtained from Namco and all of the snowpits but not for those from DM, YL and TH glaciers and other stations $(200 \%)$ in the model calculations ${ }^{60}$. The carbon isotope signatures of $\mathrm{BC}$ for the snowpit and aerosol samples were assessed using a statistical source apportionment model to quantify relative contributions from the three major emission source classes: biomass, coal and liquid fossil fuels (for example, petroleum, gasoline and diesel $)^{31}$. The comprehensive uncertainties associated with this approach were assessed using Andersson and colleagues' Bayesian Markov Chain Monte Carlo numerical simulation procedure ${ }^{31}$.

Assessment of snowpit BC collection efficiency. The BC-collection efficiency of the filtration of melted snow samples was investigated. Adding a coagulant, such as $\mathrm{NH}_{4} \mathrm{H}_{2} \mathrm{PO}_{4}$, has been shown to increase the BC-collection efficiency of filtration ${ }^{57,58}$. Hence, this technique's BC-collection efficiency level was tested by adding (or not adding) $\mathrm{NH}_{4} \mathrm{H}_{2} \mathrm{PO}_{4}$ to 16 snowpit samples before filtration. More specifically, the melted snow sample was divided into equal parts, $\mathrm{NH}_{4} \mathrm{H}_{2} \mathrm{PO}_{4}(1.5 \mathrm{~g}$ per $100 \mathrm{ml}$ of sample) was added to one of the subsamples, and the mixture was then magnetically stirred for $10 \mathrm{~min}$. All subsamples (with and without $\mathrm{NH}_{4} \mathrm{H}_{2} \mathrm{PO}_{4}$ ) were then simultaneously filtered through quartz filters for WIOC and $\mathrm{BC}$ concentration measuremen ${ }^{57}$. The ratio of the $\mathrm{BC}$ contents in samples with and without $\mathrm{NH}_{4} \mathrm{H}_{2} \mathrm{PO}_{4}$ was determined to be $77 \pm 17 \%$ (Supplementary Fig. 1), which denotes a fairly high degree of recovery. These values were slightly higher than those found for snow samples collected in Japan (69\%) (ref. 57), and they were much higher than those found for precipitation samples (38\%) (ref. 58). Hence, the 
BC collected via the filtration method without $\mathrm{NH}_{4} \mathrm{H}_{2} \mathrm{PO}_{4}$ in this work corresponds to the majority of the $\mathrm{BC}$ in each sample. Achieving such high $\mathrm{BC}$-recovery rates from TP snowpit samples is reasonable. Indeed, the BC grain-size distributions in snow tend to be larger than those in rainwater, resulting in higher BC collection efficiencies for snow samples ${ }^{61}$, as reported for snow samples from $\operatorname{Japan}^{57}$. In addition, a previous study suggested that the filter efficiency of quartz filters can be influenced by several factors, such as possible WIOC loading on filters and $\mathrm{BC}$ grain sizes ${ }^{62}$. The WIOC/BC ratio of the TP snowpit sample examined here is much higher than those reported for the European $\mathrm{Alps}^{26}$ and Japan ${ }^{57}$, and thus, we assumed that heavy WIOC loading on filters increases the $\mathrm{BC}$ collection efficiency. Kuchiki et al. also suggested that

'compacted BC aggregates and BC dust aggregates often form in snow samples without a coagulant, suggesting that the larger-size snow impurities in the natural snow samples led to the high collection efficiency of the quartz fibre filter even without a coagulant ${ }^{57}$.

This is likely true for the glacier snowpit we examined, in which we observed some visible particles. Furthermore, previous studies have reported high BC collection efficiencies for glacier samples from the $\mathrm{TP}^{13}$ and elsewhere ${ }^{63,64}$.

Taken together, these results indicate that although not all $\mathrm{BC}$ can be collected from melted snow by filtering directly through quartz filters, high recoveries are possible. Furthermore, making a first-order assumption that any $\mathrm{BC}$ loss should proportionally affect $\mathrm{BC}$ derived from fossil fuel and biomass burning, resulting in negligible effects on the determined carbon isotopic composition, seems reasonable.

Potential influence of charring on $\mathbf{B C}$ concentrations. The putative effects of the inadvertent inclusion of instrument-induced pyrolysed-C (PyrC from OC) in the ${ }^{14} \mathrm{C}$-EC isolate were considered. The formation and subsequent oxidative removal of PyrC constitute a well-recognized process that is inherent in the design of the Sunset-TOT method. The PyrC is accounted for by monitoring the laser transmission signal through the filter online, and this method is designed to burn off any remaining PyrC during the subsequent oxidation step. However, this process may also introduce a certain degree of carbon mixing from different sources (that is, some 'true' EC is burned off as $\mathrm{PyrC}$, and some PyrC is included in the observed EC fraction). However, this potential mixing effect is not expected to substantially influence concentration estimates because the mass absorption cross-sections of PyrC and EC are assumed to be similar. Indeed, several sensitivity tests of this hypothetical charring-exchange process have demonstrated that its effect should be minimal $^{21,65}$. Furthermore, in this study, the particle load was kept as low as possible, and the WIOC/BC ratios of the snowpit samples were similar to those found in aerosols (Supplementary Table 3 and Fig. 3); both of these points suggest a low risk of charring.

Data availability. All data will be publicly available in Stockholm University's Bolin Centre Database (http://bolin.su.se/data/).

\section{References}

1. Qin, Y. \& Xie, S. Spatial and temporal variation of anthropogenic black carbon emissions in China for the period 1980-2009. Atmos. Chem. Phys. 12, 4825-4841 (2012).

2. Bond, T. C. et al. Bounding the role of black carbon in the climate system: a scientific assessment. J. Geophys. Res. Atmos. 118, 5380-5552 (2013).

3. IPCC. Climate Change 2013. in Contribution of Working Group I to the Fifth Assessment Report of the Intergovernmental Panel on Climate Change Rep (Cambridge Univeristy Press, 2013).

4. Lu, Z., Streets, D. G., Zhang, Q. \& Wang, S. A novel back-trajectory analysis of the origin of black carbon transported to the Himalayas and Tibetan Plateau during 1996-2010. Geophys. Res. Lett. 39, L01809 (2012).

5. Menon, S. et al. Black carbon aerosols and the third polar ice cap. Atmos. Chem. Phys. 10, 4559-4571 (2010).

6. Ramanathan, V. \& Carmichael, G. Global and regional climate changes due to black carbon. Nat. Geosci. 1, 221-227 (2008).

7. Prell, W. L. \& Kutzbach, J. E. Sensitivity of the Indian monsoon to forcing parameters and implications for its evolution. Nature 360, 647-652 (1992).

8. Ramanathan, V. et al. Atmospheric brown clouds: hemispherical and regional variations in long-range transport, absorption, and radiative forcing. J. Geophys. Res. Atmos. 112, D22S21 (2007).

9. Flanner, M. G., Zender, C. S., Randerson, J. T. \& Rasch, P. J. Present-day climate forcing and response from black carbon in snow. J. Geophys. Res. Atmos. 112, D11202 (2007).

10. Kaspari, S. D. et al. Recent increase in black carbon concentrations from a Mt. Everest ice core spanning 1860-2000 AD. Geophys. Res. Lett. 38, L04703 (2011).

11. McConnell, J. R. et al. 20th-century industrial black carbon emissions altered arctic climate forcing. Science 317, 1381-1384 (2007).
12. Qu, B. et al. The decreasing albedo of the Zhadang glacier on western Nyainqentanglha and the role of light-absorbing impurities. Atmos. Chem. Phys. 14, 11117-11128 (2014).

13. Xu, B. et al. Black soot and the survival of Tibetan glaciers. Proc. Natl Acad. Sci. USA 106, 22114-22118 (2009).

14. He, C. et al. A global 3-D CTM evaluation of black carbon in the Tibetan Plateau. Atmos. Chem. Phys. 14, 7091-7112 (2014).

15. Kopacz, M. et al. Origin and radiative forcing of black carbon transported to the Himalayas and Tibetan Plateau. Atmos. Chem. Phys. 11, 2837-2852 (2011).

16. Ji, Z., Kang, S., Cong, Z., Zhang, Q. \& Yao, T. Simulation of carbonaceous aerosols over the Third Pole and adjacent regions: distribution, transportation, deposition, and climatic effects. Clim. Dyn. 45, 2831-2846 (2015).

17. Zhang, R. et al. Quantifying sources, transport, deposition, and radiative forcing of black carbon over the Himalayas and Tibetan Plateau. Atmos. Chem. Phys. 15, 6205-6223 (2015).

18. Zhao, Z. et al. Aerosol particles at a high-altitude site on the Southeast Tibetan Plateau, China: implications for pollution transport from South Asia. J. Geophys. Res. Atmos. 118, 11360-11375 (2013).

19. Cong, Z. et al. Carbonaceous aerosols on the south edge of the Tibetan Plateau: concentrations, seasonality and sources. Atmos. Chem. Phys. 15, 1573-1584 (2015).

20. Budhavant, K. et al. Radiocarbon-based source apportionment of elemental carbon aerosols at two South Asian receptor observatories over a full annual cycle. Environ. Res. Lett. 10, 064004 (2015).

21. Chen, B. et al. Source forensics of black carbon aerosols from China. Environ. Sci. Technol. 47, 9102-9108 (2013).

22. Gustafsson, Ö. et al. Brown clouds over South Asia: biomass or fossil fuel combustion? Science 323, 495-498 (2009).

23. Szidat, S. et al. Contributions of fossil fuel, biomass-burning, and biogenic emissions to carbonaceous aerosols in Zurich as traced by 14C. J. Geophys. Res 111, D07206 (2006).

24. Zhang, Y. L. et al. On the isolation of OC and EC and the optimal strategy of radiocarbon-based source apportionment of carbonaceous aerosols. Atmos. Chem. Phys. 12, 10841-10856 (2012).

25. Szidat, S. et al. Fossil and non-fossil sources of organic carbon (OC) and elemental carbon (EC) in Goteborg, Sweden. Atmos. Chem. Phys. 9, 1521-1535 (2009).

26. Jenk, T. M. et al. Radiocarbon analysis in an Alpine ice core: record of anthropogenic and biogenic contributions to carbonaceous aerosols in the past (1650-1940). Atmos. Chem. Phys. 6, 5381-5390 (2006).

27. Qian, Y., Flanner, M. G., Leung, L. R. \& Wang, W. Sensitivity studies on the impacts of Tibetan Plateau snowpack pollution on the Asian hydrological cycle and monsoon climate. Atmos. Chem. Phys. 11, 1929-1948 (2011).

28. Jacobson, M. Z. Climate response of fossil fuel and biofuel soot, accounting for soot's feedback to snow and sea ice albedo and emissivity. J. Geophys. Res. Atmos. 109, D21201 (2004).

29. Sharma, S. et al. 16-year simulation of Arctic black carbon: transport, source contribution, and sensitivity analysis on deposition. J. Geophys. Res. Atmos. 118, 943-964 (2013).

30. Zhao, Y., Nielsen, C. P., Lei, Y., McElroy, M. B. \& Hao, J. Quantifying the uncertainties of a bottom-up emission inventory of anthropogenic atmospheric pollutants in China. Atmos. Chem. Phys. 11, 2295-2308 (2011).

31. Andersson, A. et al. Regionally-varying combustion sources of the January 2013 severe haze events over eastern China. Environ. Sci. Technol. 49, 2038-2043 (2015).

32. Jacobson, M. Z. Short-term effects of controlling fossil-fuel soot, biofuel soot and gases, and methane on climate, Arctic ice, and air pollution health. J. Geophys. Res. Atmos. 115, D14209 (2010).

33. Gustafsson, Ö. \& Ramanathan, V. Convergence on climate warming by black carbon aerosols. Proc. Natl Acad. Sci. USA 113, 4243-4245 (2016).

34. Szidat, S. et al. Source apportionment of aerosols by ${ }^{14} \mathrm{C}$ measurements in different carbonaceous particle fractions. Radiocarbon 46, 475-484 (2004).

35. Lüthi, Z. L. et al. Atmospheric brown clouds reach the Tibetan Plateau by crossing the Himalayas. Atmos. Chem. Phys. Discuss. 14, 28105-28146 (2014).

36. Ramanathan, V. et al. Warming trends in Asia amplified by brown cloud solar absorption. Nature 448, 575-578 (2007).

37. Xia, X. et al. Baseline continental aerosol over the central Tibetan Plateau and a case study of aerosol transport from South Asia. Atmos. Environ. 45, 7370-7378 (2011).

38. Decesari, S. et al. Chemical composition of PM 10 and PM 1 at the highaltitude Himalayan station Nepal Climate Observatory-Pyramid (NCOP)(5079m asl). Atmos. Chem. Phys. 10, 4583-4596 (2010).

39. Marinoni, A. et al. High black carbon and ozone concentrations during pollution transport in the Himalayas: five years of continuous observations at NCO-P global GAW station. J. Environ. Sci. 25, 1618-1625 (2013).

40. Marinoni, A. et al. Aerosol mass and black carbon concentrations, a two year record at NCO-P (5079m, Southern Himalayas). Atmos. Chem. Phys. 10, 8551-8562 (2010). 
41. Xu, B.-Q. et al. Deposition of anthropogenic aerosols in a southeastern Tibetan glacier. J. Geophys. Res. Atmos. 114, D17209 (2009).

42. Zhang, Y.-L. et al. Source apportionment of elemental carbon in Beijing, China: insights from radiocarbon and organic marker measurements. Environ. Sci. Technol. 49, 8408-8415 (2015).

43. Zhang, Y.-L. et al. Radiocarbon-based source apportionment of carbonaceous aerosols at a regional background site on Hainan Island, South China. Environ. Sci. Technol. 48, 2651-2659 (2014).

44. Li, C. et al. Concentrations and light absorption characteristics of carbonaceous aerosol in PM2.5 and PM10 of Lhasa city, the Tibetan Plateau. Atmos. Environ. 127, 340-346 (2016).

45. Bonasoni, P. et al. Atmospheric brown clouds in the Himalayas: first two years of continuous observations at the Nepal-Climate Observatory at Pyramid (5079m). Atmos. Chem. Phys. Discuss. 10, 4823-4885 (2010).

46. Granat, L., Engstrom, J. E., Praveen, S. \& Rodhe, H. Light absorbing material (soot) in rainwater and in aerosol particles in the Maldives. J. Geophys. Res. Atmos. 115, D16307 (2010).

47. Pio, C. A. et al. Climatology of aerosol composition (organic versus inorganic) at nonurban sites on a west-east transect across Europe. J. Geophys. Res. Atmos. 112, D23S02 (2007).

48. Wang, M. et al. Carbonaceous aerosols recorded in a southeastern Tibetan glacier: analysis of temporal variations and model estimates of sources and radiative forcing. Atmos. Chem. Phys. 15, 1191-1204 (2015).

49. Ming, J., Xiao, C., Du, Z. \& Yang, X. An overview of black carbon deposition in high Asia glaciers and its impacts on radiation balance. Adv. Water Resour. 55, 80-87 (2013).

50. Li, C. et al. Personal PM 2.5 and indoor CO in nomadic tents using open and chimney biomass stoves on the Tibetan Plateau. Atmos. Environ. 59, 207-213 (2012).

51. Chen, P., Kang, S., Bai, J., Sillanpää, M. \& Li, C. Yak dung combustion aerosols in the Tibetan Plateau: Chemical characteristics and influence on the local atmospheric environment. Atmos. Res. 156, 58-66 (2015).

52. Xiao, Q. et al. Indoor air pollution from burning yak dung as a household fuel in Tibet. Atmos. Environ. 102, 406-412 (2015).

53. Kehrwald, N. M. et al. Mass loss on Himalayan glacier endangers water resources. Geophys. Res. Lett. 35, L22503 (2008).

54. Kang, S. et al. Dramatic loss of glacier accumulation area on the Tibetan Plateau revealed by ice core tritium and mercury records. Cryosphere 9, 1213-1222 (2015).

55. Yao, T. et al. Different glacier status with atmospheric circulations in Tibetan Plateau and surroundings. Nat. Clim. Change 2, 663-667 (2012).

56. Slater, J. F., Currie, L. A., Dibb, J. E. \& Benner, Jr B. A. Distinguishing the relative contribution of fossil fuel and biomass combustion aerosols deposited at Summit, Greenland through isotopic and molecular characterization of insoluble carbon. Atmos. Environ. 36, 4463-4477 (2002).

57. Kuchiki, K. et al. Elemental carbon, organic carbon, and dust concentrations in snow measured with thermal optical and gravimetric methods: variations during the 2007-2013 winters at Sapporo, Japan. J. Geophys. Res. Atmos. 120, 868-882 (2015).

58. Torres, A., Bond, T. C., Lehmann, C. M. B., Subramanian, R. \& Hadley, O. L. Measuring organic carbon and black carbon in rainwater: evaluation of methods. Aerosol Sci. Technol. 48, 239-250 (2014).

59. Levin, I., Kromer, B., Schmidt, M. \& Sartorius, H. A novel approach for independent budgeting of fossil fuel $\mathrm{CO} 2$ over Europe by (CO2)-C-14 observations. Geophys. Res. Lett. 30, 2194 (2003).

60. Klinedinst, D. B. \& Currie, L. A. Direct quantification of PM2.5 fossil and biomass carbon within the Northern Front Range Air Quality Study's domain. Environ. Sci. Technol. 33, 4146-4154 (1999).

61. Schwarz, J. P. et al. Assessing single particle soot photometer and integrating sphere/integrating sandwich spectrophotometer measurement techniques for quantifying black carbon concentration in snow. Atmos. Meas. Tech. 5, 2581-2592 (2012)
62. Lim, S. et al. Refractory black carbon mass concentrations in snow and ice: method evaluation and inter-comparison with elemental carbon measurement. Atmos. Meas. Tech. 7, 3307-3324 (2014).

63. Lavanchy, V. M. H., Gaggeler, H. W., Schotterer, U., Schwikowski, M. \& Baltensperger, U. Historical record of carbonaceous particle concentrations from a European high-alpine glacier (Colle Gnifetti, Switzerland). J. Geophys. Res. Atmos. 104, 21227-21236 (1999).

64. Lavanchy, V. M. H., Gäggeler, H. W., Nyeki, S. \& Baltensperger, U. Elemental carbon (EC) and black carbon (BC) measurements with a thermal method and an aethalometer at the high-alpine research station Jungfraujoch. Atmos. Environ. 33, 2759-2769 (1999).

65. Winiger, P., Andersson, A., Yttri, K. E., Tunved, P. \& Gustafsson, O. Isotope-based source apportionment of EC aerosol particles during winter high-pollution events at the Zeppelin Observatory, Svalbard. Environ. Sci. Technol. 49, 11959-11966 (2015).

66. Wang, R. et al. Exposure to ambient black carbon derived from a unique inventory and high-resolution model. Proc. Natl Acad. Sci. USA 111, 2459-2463 (2014).

\section{Acknowledgements}

This work was funded by the National Natural Science Foundation of China (41421061, 41225002, and 41271015), the State Key Laboratory of Cryosphere Science (SKLCS-ZZ-2016), the Strategic Priority Research Program (B) of the Chinese Academy of Sciences (XDB03030504) and the Swedish research funding agency Formas and The Swedish Energy Agency (STEM). C.B. acknowledges additional financial support from the EU Marie Curie Programme (PIEF-GA-2011-198507). We acknowledge Dr Maheswar Rupakheti of the Sustainable Atmosphere for the Kathmandu Valley Project (SusKat, Institute for Advanced Sustainability Studies, Germany) and Dr Arnico Panday of the International Centre for Integrated Mountain Development (ICIMOD) for assisting with the TSP sampling campaign in Nepal.

\section{Author contributions}

S.K., Ö.G., C.L. and D.Q. designed the experiment. C.L., S.K. and Ö.G. wrote the paper. Q.Z. and Z.C. collected the samples. C.L., P.C., C.B. and B.C. conducted the experiment. A.A. performed the numerical simulation procedure.

\section{Additional information}

Supplementary Information accompanies this paper at http://www.nature.com/ naturecommunications

Competing financial interests: The authors declare no conflict of interests.

Reprints and permission information is available online at http://npg.nature.com/ reprintsandpermissions/

How to cite this article: Li, C. et al. Sources of black carbon to the Himalayan-Tibetan Plateau glaciers. Nat. Commun. 7:12574 doi: 10.1038/ncomms12574 (2016).

This work is licensed under a Creative Commons Attribution 4.0 International License. The images or other third party material in this article are included in the article's Creative Commons license, unless indicated otherwise in the credit line; if the material is not included under the Creative Commons license, users will need to obtain permission from the license holder to reproduce the material. To view a copy of this license, visit http://creativecommons.org/licenses/by/4.0/

(C) The Author(s) 2016 